\title{
AKTIVOITU YLEISÖ SUOMEN BIG BROTHERIN INTERNET-KESKUSTELUPALSTALLA
}

\begin{abstract}
Artikkelissa tarkastellaan yleisön, tekstin ja tuotannon välisiä subteita. Aineistona käytetään Suomen Big Brotherin virallisella internet-keskustelupalstalla käytyä keskustelua. Big Brotherin kaltaiset osallistavat monimediaformaatit tarjoavat yleisölle mabdollisuuden osallistua mediatekstin muotoutumiseen ja jopa vaikuttaa suoraan tuotannon toimiin. Tällainen vuorovaikutteisuus tuo yleisön ja tuotannon toimijuudet lähemmäksi toisiaan, mikä voi aiheuttaa erityispiirteitä yleisön subtautumisessa tekstiin.

Artikkelissa osallistutaan keskusteluun kulttuurintutkimuksessa käytetystä "aktiivisen yleisön" käsitteestä ja tarkastellaan Big Brotherin yleisöä aktivoidun yleisön käsitteen kautta. Tämän uuden käsitteen avulla pyritään kiinnittämä̈̈n buomio erityisesti yleisön ja tekstin subteisiin sekä näibin subteisiin liittyviin molemminpuolisiin panostuksiin: ajatus aktivoidusta yleisöstä sisältää sekä yleisön aktiivisen toimijuuden tekstin ja sen merkitysten muotoutumisessa että tekstin aktiivisen toimijuuden, pyrkimyksen kutsua yksilöitä osaksi tekstiä ja panostamaan omaan yleisöyteensä.
\end{abstract}

Kulttuurintutkimuksessa on keskusteltu runsaasti tavasta käsitteellistää median välittämien merkitysten muodostumisprosesseja. Niin sanottua "aktiivisen yleisön" paradigmaa on pidetty vastavetona Frankfurtin koulukunnan näkemyksille. Marxilaiseen yhteiskuntateoriaan nojaava Frankfurtin koulukunta käsittää joukkoviestinnän kulttuuriteollisuutena, joka ohjaa huomion pois merkittävistä yhteiskunnallisista kysymyksistä luomalla vääriä tarpeita ja mielihaluja. Yleisö puolestaan näyttäytyy manipuloitavana passiivisena massana, jonka oma valinnanvapaus ja oma tahto on vain näennäistä, koska massakulttuurissa valinta tapahtuu lopulta aina valtaapitävien määrittelemästä tarjonnasta. (Ks. esim. Horkheimer \& Adorno 1933/2004.) Tätä elitististä, populaarikulttuuria ja "suurta yleisöä" väheksyvää näkemystä on kulttuurin- 
tutkimuksessa kritisoitu korostamalla merkitysten muotoutumisen kontekstisidonnaisuutta ja yleisön aktiivista roolia mediatekstien tulkitsijoina, joilla on mahdollisuus myös tekstin sisältämiä hegemonisia merkityksiä haastavaan ja vastustavaan luentaan. Tietä tällaiselle tutkimukselle avasi Stuart Hallin sisäänkoodaus/uloskoodaus -malli (encoding/decoding, Hall 1973). (Ks. esim. Alasuutari 1999, 2-13; Gray 1999, 26-30.)

Yleisön aktiivisuuden käsite pureutuu siis nimenomaan tekstin tuotannon ja vastaanoton välisen vallan kysymykseen: missä tekstien merkitykset muotoutuvat, ovatko ne tuottajan sisäänkoodaamia vai yleisön omien kontekstiensa mukaisesti neuvotellen tekstin pohjalta tuottamia? Populaarikulttuuriin positiivisesti suhtautuvan ja yleisön toiminnalle arvoa antavan aktiivisen yleisön teorian äärimmäisenä edustajana pidetään John Fiskeä, joka korostaa yleisön valtaa merkityksentuotannossa ja jonka mukaan "populaarikulttuuri on ihmisten tekemää, ei kulttuuriteollisuuden tuottamaa" (Fiske 1989, 23-24). Ansioistaan huolimatta Fiske menee kuitenkin optimismissaan kenties liian pitkälle, ja häntä onkin kritisoitu yleisön vastarintaisuuden fetissoimisesta sekä mediakulttuurin manipuloivien ja konservatiivisten vaikutusten huomiotta jättämisestä (ks. esim. Kellner 1998, 46-55). Samalla koko aktiivisen yleisön teoriaa hyödyntävä yleisötutkimus on leimautunut monien yhteiskunta- ja kulttuuriteoreetikkojen silmissä liian teksti- ja yleisökeskeiseksi, kulttuurituotannon ja -kulutuksen yhteiskunnallis-poliittisen kontekstin sivuuttavaksi, vaikka yksittäisiä tutkimuksia tarkastellen tällainen kritiikki paljastuu usein aiheettomaksi (Gray 1999, 25).

Ien Ang esittelee jo kymmenen vuotta sitten ilmestyneessä kirjassaan Living Room Wars: Retbinking Media Audiences for a Postmodern World mielestäni osuvan näkemyksen yleisön aktiivisuuden ja tuotannon vallan suhteesta. Angin mukaan nykyisessä kaupallisvetoisessa ja pirstaloituvassa mediakulttuurissa kulttuurinen logiikka edellyttää, että yleisöjen (eli meidän kaikkien) on oltava aktiivisia. On valittava ja vaadittava valinnanvaraa, tulkittava ja annettava merkityksiä, jotta meidän olisi ylipäätään mahdollista tehdä mitään tolkkua valtavasta mediamassasta, jonka keskellä elämme. Yleisön kyvystä analysoida kriittisesti kuluttamiaan tuotteita on tullut lähtöoletus, sillä "postmoderni kulutuskulttuuri edellyttää ihmisten olevan semioottisesti taitavampia, sivistyneempiä tai merkityksellistämiskyvyiltään oppineita”. Ang korostaakin, että kriittisyys ja yleisön aktiivisuus eivät suinkaan välttämättä merkitse vastarintaa ja median vallan horjuttamista, eikä yleisön aktiivisuuden käsitettä tulisi nähdä "passiivisen yleisön” käsitteen purkajana. Se olisi hahmotettava nimenomaan postmodernissa maailmassa elävien ihmisten kohtaamien ristiriitojen ja niiden neuvottelun kautta. Ang kehottaa näin pyrkimään eroon "aktiivisen yleisön" ja "kulttuuriteollisuuden" vastakkainasettelusta, ja peräänkuuluttaa yleisötutkimusta, joka ottaa huomioon taloudellisten valtarakenteiden, markkinavoimien ja kapitalismin analyysin aliarvioimatta silti yleisön merkitystuotannon merkitystä. (Ang 1996, 10-14.)

Tämä on mielestäni hyvä lähtökohta erityisesti kaupallisesti tuotettujen mediatekstien yleisösuhteen tarkasteluun. Nykyisessä populaarikulttuurissa yleisön osallistaminen ja kaksisuuntaisen yhteyden luominen tekstin ja yleisön välille on yhä useammin menestystarinoiden takana - kuten myös Big Brother -formaatin tapauksessa. Estella Tincknell ja Parvati Raghuram näkevät Big Brotherin yleisön uudenlaisena esimerkkinä kulttuurintutkimuksen aktiivi- 
sesta yleisöstä: yleisön aktiivinenkin suhde tekstiin on perinteisesti ajateltu "tekstin ulkopuoliseksi", se on tarkoittanut älyllistä työskentelyä tekstin kanssa, ei puuttumista itse tekstiin ja sen tuottamiseen (Tincknell \& Raghuram 2004, 253-254). Big Brotherin tyyppiset osallistavat ohjelmat puolestaan "kutsuvat yleisöä osaksi tekstiä" ("solicit the audience to 'be the text'"), mikä muuttaa yleisön, tekstin ja tuotannon suhteita (emt., 258; vrt. van Zoonen 2005, 55).

Tällaisen yleisösuhteen tarkastelun välineeksi ehdotan aktivoidun yleisön käsitettä. ${ }^{1}$ Pyrin tällä käsitteellä kiinnittämään huomion erityisesti yleisön ja tekstin suhteisiin ja näihin suhteisiin liittyviin molemminpuolisiin panostuksiin: ajatus aktivoidusta yleisöstä sisältää sekä yleisön aktiivisen toimijuuden tekstin ja sen merkitysten muotoutumisessa että tekstin aktiivisen toimijuuden, pyrkimyksen kutsua yksilöitä (kuluttajia) osaksi tekstiä ja panostamaan omaan yleisöyteensä.

Tässä artikkelissa määrittelen ja perustelen aktivoidun yleisön käsitettä Big Brother -ohjelman keskustelupalstan analyysin kautta. Tutkin, miten aktivoitu yleisö tulkitsee, kontekstoi ja merkityksellistää Big Brother -tekstiä. Big Brother -tekstillä viittaan koko monimediaaliseen seuraamiskokemukseen, ${ }^{2}$ ja tähän monimediaalisuuteen tarttuakseni käytän aineistona Suomen Big Brotherin yleisön keskustelua internet-keskustelupalstalla, joka kuuluu Big Brother -formaattiin.

Tarkastelun kohteena on siis ohjelman kotisivulta linkitetty ja Subtvःn/ MTV3:n ylläpitämä palsta, jolla käytävää keskustelua Big Brotherin tuotanto seuraa ja rohkaisee. ${ }^{3}$ Aineisto on kerätty Suomen ensimmäisen Big Brother -tuotantokauden aikana eli 28.8.-1.12.2005. Seurasin palstaa aktiivisesti koko tuotantokauden ajan ja tallensin tietokoneen kovalevylle kokonaisia keskusteluketjuja. Pyrin saamaan talteen mahdollisimman monenlaisia ja eri aiheita käsitteleviä ketjuja. Aineiston analyysini perustuu osittain myös keskustelun jatkuvaan seuraamiseen eli eräänlaiseen osallistuvaan havainnointiin (tosin en itse osallistunut keskusteluun), ei pelkästään tallennettuun aineistoon. Tarkastelen tätä yleisöyhteisöä kysymällä, millaiseksi Big Brotherin seuraamiskokemus ja yleisöön kuuluminen internet-keskusteluissa rakentuu? Kuinka omaa paikkaa katsojana määritellään ja millaisia valta-asetelmia yleisön, tekstin ja tuotannon välille muodostuu? Pohdin myös, voiko tästä jäljittää yleisemmin nykyisen mediakulttuurin erityispiirteitä ja kehityssuuntia.

Futurama-animaatiosarjan fanien toimintaa verkossa tutkinut Steve Bailey kirjoittaa, että vaikka internetin nopeasti lisääntyvän käytön myötä myös tietokonevälitteinen viestintä on otettu viestintätieteissä tutkimuksen kohteeksi, internetin paikkaa mediakentällä ja sen vaikutusta viestintäkäytäntöihin laajemmassa yhteydessä ei ole vielä tutkittu kovin laajalti. Bailey esittää, että erityisesti mediayleisöjen tutkimuksessa tulisi ottaa huomioon internetin vaikutukset sekä uusien diskurssien tarjoajana että jo olemassa olevien yleisökäytäntöjen muokkaajana. (Bailey 2002, 239-240.) Baileyn artikkelin ilmestymisen jälkeen yleisö- ja fanitutkimuksessa onkin tehty paljon tutkimuksia, joissa myös internetin rooli on vahvasti läsnä (esim. Tincknell \& Raghuram 2004; Holmes 2004; Nikunen 2005; Leed 2005; Laukkanen 2003), ja tähän jatkumoon myös oma tutkimukseni liittyy.

Big Brother ei kuitenkaan ole erityinen ja kiinnostava nykyisen mediakulttuurin ilmiö vain vuorovaikutuksellisuutensa ja monimediaalisuutensa vuoksi, 
vaan sen puhuttelevuus johtuu pitkälti myös sen sisällöstä - formaatin huomioarvo perustuu nähdäkseni sen saamaan (ja sille rakennettuun) statukseen kokonaisuudessaan uudenlaisena televisio-ohjelmana. Tästä syystä lähden liikkeelle paikantamalla Big Brother -mediatuotteen sijaintia televisioviihteen kentällä sisällön näkökulmasta.

\section{TUTKIMUSKOHTEENA TODELLISUUSTELEVISIOFORMAATIN YLEISÖSUHDE}

Suomalaiset televisionkatsojat on edellisten kymmenen vuoden aikana tutustutettu runsaaseen tarjontaan erilaisia viihdeohjelmia, joissa kuvataan tavallisten ihmisten toimintaa ja tunnekokemuksia erilaisissa (usein keinotekoisissa) sosiaalisissa tilanteissa hyvin melodramaattiseen ja skandaalihakuiseen sävyyn. Englanninkieliseen reality television -termiin perustuen tämäntyyppisiä ohjelmia on alettu yleisesti nimittää "tosi-TV:ksi" ja niistä puhutaan usein ikään kuin kyseessä olisi yksi yhteneväinen ohjelmatyyppi. Itse asiassa "tosiTV"-sateenvarjokäsitteen alle mahtuu niin sisällöltään kuin muodoltaankin hyvin erilaisia ohjelmia ja monien "perinteisten" ohjelmatyyppien yhdistelmiä eli genrehybridejä. ${ }^{4}$ Reality- eli todellisuusviihdettä ei mielestäni voikaan lokeroida omaksi erilliseksi kokonaisuudekseen TV-tuotannon kentällä, vaan kyseessä on sekä tuotannon että vastaanoton asenne- ja toimintamalli, jota voidaan soveltaa hyvin erilaisissa (viihde/)tuotannoissa.

Luokittelua tai sen purkamista oleellisempaa ja mielenkiintoisempaa onkin tarkastella juuri niitä sisällöllisiä elementtejä, joita pidetään leimallisina tosi-TV:lle, sekä niitä erityisiä tuotannon ja yleisön välisiä suhteita, jotka ovat herättäneet keskustelua todellisuusviihteestä "uudenlaisena" ja mullistavana television muotona (ks. esim. Kilborn 2003; Murray \& Ouellette 2004, 1-3). Big Brother on yksi suosituimmista todellisuustelevisioformaateista ja se on vaikuttanut vahvasti koko ilmiön kehitykseen. Sitä tarkastelemalla voidaankin löytää tosi-tv-ilmiölle tunnusomaisia piirteitä.

Ensiksi, tärkeä osa Big Brotherin ohjelmaideaa on tavallisten ihmisten nostaminen katseen kohteeksi, TV-julkkiksiksi. Mielestäni tämä "vertaistekijä" on yksi todellisuusviihteen viehätyksen ja menestyksen syitä, sillä se luo yleisön ja ruudulla esiintyvien hahmojen välille läheisemmän suhteen kuin esimerkiksi fiktiosarjojen kohdalla: katsoja voi kokea olevansa samalla tasolla ohjelmiin osallistuvien "tavisten" kanssa, toisin kuin esimerkiksi tähtinäyttelijöiden kanssa. Katsoja voi vertailla näkemäänsä televisiotodellisuutta omaan elämäänsä ja arvioida, kuinka itse toimisi, jos olisi ruudun toisella puolella. Juuri tätä on todellisuusviihteen todellisuus, yleisölle tarjottava valta-asema niin sanottujen tavallisten ihmisten ja väitetysti aitojen tapahtumien tirkistelijänä ja niiden autenttisuuden arvioijana. (Hautakangas 2004, 46-47; Hautakangas 2005, 154; vrt. Hill 2005, 58, 78.)

Toiseksi, todellisuusviihteen sisällöille on tavallista hyvän maun ja normien rajojen koettelu, ja tällaista ohjelmistoa leimaa vahvasti maine moraalisesti arveluttavana viihteen muotona, "törky-TVःnä". Myös Big Brother on saanut kulloisessakin esitysmaassaan osakseen paitsi korkeita katsojalukuja, myös ankaraa arvostelua ja paheksuntaa (ks. esim. Biltereyst 2004; Hill \& Palmer 2002). ${ }^{5}$ Todellisuusviihteeseen liitetään senkaltaista hömpän ja arvottoman 
ajanhukan kritiikkiä, jota on totuttu kuulemaan esimerkiksi saippuaoopperoiden kohdalla (vrt. esim. Ang 1985, 89-92) sekä toisaalta samanlaisia syytöksiä yhteiskunnan moraalin rappeuttamisesta ja alhaiseen tirkistelynhaluun vetoamisesta, kuin millä on tapana paheksua viihteellisten viikkolehtien eli niin sanotun keltaisen lehdistön toimintatapoja (vrt. Hautakangas 2005; Keskitalo, Palomaa ja Sainio 2005; ks. myös Töyry 2005).

Myös tässä on merkitystä sillä, että kuvatut henkilöt ovat "taviksia" ja tapahtumat ei-näyteltyjä. On kyse siitä, mitä kaikkea yhtäältä television tuottajat laittavat ihmiset tekemään, toisaalta mitä ihmiset suostuvat tekemään julkisesti, jopa miljoonien katsojien edessä. Kolmannesta näkökulmasta voidaan myös pohtia, miksi yleisö haluaa katsoa tällaista tirkistelynhaluun ja skandaalinnälkään vetoavaa viihdettä. Todellisuustelevisioilmiö kuuluukin osaltaan keskusteluun "tabloidisaatioksi" kutsutusta median viihteellistymisestä ja sensationaalistumisesta. Annette Hill toteaa, "populaari todellisuuspohjainen televisio-ohjelmisto ${ }^{6}$ (popular factual television) on kehittynyt tabloidjournalismin, televisiodokumentin ja populaariviihteen ristiinhedelmöityksen aikana" (Hill 2005, 23; vrt. Glynn 2000; myös Griffen-Foley 2004).

Kolmanneksi, ei sovi unohtaa myöskään kaupallista televisiotoimintaa ohjaavien markkinatalouden lainalaisuuksien merkitystä. Todellisuustelevisioilmiön kehitys ja menestys on kytköksissä televisiotuotannon rakenteellisiin muutoksiin, kuten taloudellisista paineista seuranneeseen globaalin formaattikaupan yleistymiseen (ks. esim. Moran 1998; Magder 2004; Raphael 2004) sekä median digitaalistumisen myötä syntyneeseen tarpeeseen monimediaalisten (eli mediarajat ylittävien ja internetin tarjoamaa interaktiivisuutta hyödyntävien) tuotteiden kehittämiseksi (ks. esim. Holmes 2004). Big Brother on loistava esimerkki mediateollisuuden pyrkimyksistä vastata digitaalisen murroksen haasteisiin, sillä formaatti perustuu eri mediateknologioiden hyödyntämiselle, erityisesti television ja internetin tiiviille yhdistämiselle.

Big Brother "koukuttaa" siis yleisöään sekä toiminnallisella että emotionaalisella tasolla: formaattiin kuuluu olennaisesti sekä voimakkaiden tunteiden ja kiivaiden keskustelujen herättäminen että vuorovaikutteisuus ja yleisön osallistaminen aktiivisiksi toimijoiksi. Tämä tuo tekstin tuotannon ja kulutuksen perinteisesti visusti erillään pidetyt toimijuudet lähemmäksi toisiaan.

\section{MILLAINEN FORMAATTI, SELLAINEN YLEISÖ}

Big Brotherin keskustelupalstan seuraamiskokemus tarjoaa samantapaisia nautintoja ja vaatii samankaltaista tulkintakehystä kuin itse Big Brother -televisioohjelman seuraaminen. Monet keskustelijat sanovatkin olevansa "koukussa" nimenomaan keskustelupalstaan, eivät niinkään TV-ohjelmaan. Todellisuusviihteelle tyypilliseen tapaan keskustelu tarjoaa voimakkaita affektiivisia kokemuksia ja ääritunteiden rajuja purkauksia, ja keskusteluun osallistutaan Big Brotherin emotionaaliselle taajuudelle virittyneenä - eli Big Brother -tekstiin aktivoituna (vrt. saippuaoopperoiden tulkintakehyksestä Ang 1985, 79-80). Yleisö siis omaksuu samanlaisen puheavaruuden eli diskurssin ${ }^{7}$ Big Brother -tekstin kanssa ja alkaa osaltaan tuottaa sitä itse, ottaen oman paikkansa koko katsomiskokemuksen muodostumisessa (tai, tuotannon näkökulmasta, formaatin onnistuneessa toteutuksessa): 
Kirjoittaja: morgue

Aika: 24.11.2005 0:06

Aihe: Re: Terhi bikineissä

Terhi on ruma ja lihava. Kauniit kasvot ja nuori (31v), mutta syönyt itsensä karmeaksi possuksi. Muka kasvissyöjä ja urheilullinen. Vetääkö se niiden herneiden kanssa kilon voita vai miten pystyy tuollaisen pelastusrenkaan hankkimaan vyötärölleen?

Tunnepuhe, rakastaminen ja inhoaminen ovat tunnetusti osa populaarin viihteen ja "fanittamisen" affektiivisia nautintoja (vrt. Ang 1985; Wasko 2001) Kaarina Nikunen toteaa "vihaamme Ally McBealia" -ilmiötä käsitellessään, että "[v]ihaamisen kulttuurissa on yhtä lailla kyse affektiivisesta sensibiliteetistä kuin fanikulttuurissakin. Affektiivinen suhde mediakuvastoon kertoo identiteetin rakentumisesta: se on kiihkeää neuvottelua siitä, keitä me haluamme olla, keitä emme." (Nikunen 2005, 255.)

Aggressiivinen ja affektiivinen puhetapa kohdistuu koko Big Brother -tekstiin, ei vain ohjelman kilpailijoihin. Keskustelupalstalla arvioidaan samalla armottomalla kriittisyydellä tuotannon toimia sekä toisten yleisön jäsenten esittämiä puheenvuoroja ja mielipiteitä. Siinä missä Big Brotherin osanottajat juonittelevat, sättivät toisiaan, tappelevat avoimesti tai ihastuvat tulisesti, näin toimitaan myös keskustelupalstalla kirjoittajien kesken. Tätä selittää osaltaan internetin kasvoton luonne: Big Brother -keskustelupalstan käyttäjäksi rekisteröityminen onnistuu täysin nimettömänä, ja kun tavanomaiset sosiaalisen kanssakäymisen kohteliaisuuskoodit eivät päde eikä ole vaaraa "kasvojen menettämisestä", keskustelun sävyssä korostuvat jyrkät mielipiteet ja ääritunteet (vrt. Bailey 2002, 248).

Aggressiivisuus, tylyys, toisten nolaaminen ja vähättely, väärinkäsitykset ja tahallinen harhaanjohtaminen ovatkin sinänsä varsin tavallisia internet-yhteisöllisyydessä (ks. esim. Mäyrä 1999). Big Brother -keskustelupalstaa pidetään kuitenkin vielä hieman tavallista villimpänä, ja kokeneet verkkokeskustelijat ilmaisivatkin etenkin Big Brotherin alkuvaiheessa närkästyksenä sitä kohtaan, että palstalla ei juurikaan ole "netikettiä", internet-keskustelun kirjoittamattomia sääntöjä ja kohteliaisuuskoodeja. Toisin sanoen, samalla tavoin kuin itse Big Brother -ohjelma nähdään usein televisiotarjonnan joukossa poikkeukseksi, huonoa makua ja laatua edustavaksi ja liian pitkälle meneväksi, samoin arvioidaan myös ohjelman keskustelupalstaa:

Kirjoittaja: bbsuomi

Aika: 27.09.2005 10:56

Aihe: Lakkaan seuraamasta palstaa ja sarjaa

Keskustelupalstan mielettömyyden, täydelliseen joukkohysteriaan ja vihaan sortumisen sekä kohtuuttomaan henkilökohtaiseen loukkaamiseen ja pahantahtoisuuteen menemisen takia päätin lopettaa sekä tämä palstan lukemisen että koko sarjan seuraamisen.

En voi kannattaa formaattia, joka saa ihmiset näin pahantahtoisiksi ja ilkeiksi. 
Tätä palstaa ei valvota ollenkaan ja jos olisin yksi kilpailijoista harkitsisin ulospäästyäni vakavasti syytteen nostamista palstan ylläpitäjiä ja joitain kirjoittajia vastaan.

Toisaalta tätä hillittömyyttä pidetään myös palstan etuna ja viehättävänä piirteenä, ja nimenomaan tietty hillittömyys muodostaa keskustelupalstalle oman hengen, joka valikoi foorumille osallistujia jonkin verran - netiketistä kiinni pitävät ja tiukan asiallista keskustelua haluavat saavat etsiä fooruminsa muualta:

Kirjoittaja: drno

Aika: 23.11.2005 14:49

Aihe: Ah, rakkaat palstalaiset...

...olette kuin musiikkia korvilleni..

Kävin tuolla toisessa foorumissa vähän haistelemassa tunnelmia, kun oli kehuttu, että siellä on asiallista toimintaa. Olipa kyllä asiallista. Jokaiselle kilpailijalle oli perustettu oma kotelo, johon tätä kilpailijaa koskevista hyvistä asioista sai käydä keskustelemassa. Asiallista, mutta... Tylsää.

On se mukavaa, kun täällä keskustelut sähinöi, verbaalinen sota paukkaa. Ketjuja syntyy kuin sieniä sateella ja koskaan ei ole tylsää!

Hyvä me!

Kirjoittaja: nora2010

Aika: 23.11.2005 14:54

Aihe: Ah, rakkaat palstalaiset...

En kyllä varmastikaan olisi koukussa jos tämä olisi kiva foorumi, missä kirjoitellaan vain, että Antti on kiva, Terhi on älykäs, Tiina on suloinen ja Perttu on söpö

On myös tärkeää huomata, että vaikka tunteenilmaukset keskustelupalstalla ovat voimakkaita, osa niistä on tarkoituksellisesti kärjistettyjä. Sekä keskustelupalstalla että todellisuustelevision vastaanotossa yleensä on oleellista ymmärtää yleisön joukossa tavallinen ironinen asenne koko mediakokemukseen. Ironian avulla otetaan etäisyyttä ja kevennetään vahvaa emotionaalisuutta verhoutumalla huumorin moniselitteisyyden taakse. Hyvin usein keskustelijat muistuttavat toisiaan siitä, että Big Brotherin äärellä koettua ei kannata ottaa liian vakavasti: kaikki on lopulta vain viihdettä, peliä ja leikkiä, eikä millekään nähdylle tai sanotulle tulisi antaa kovin suuria merkityksiä. Onkin lopulta usein vaikeaa päätellä, mikä palstalla sanotusta on tosissaan tarkoitettua ja mikä taas keskustelun provosoimiseksi väritettyä, harhaanjohtavaa ja jopa suoranaista valehtelua. Palstan vakituiset ja aktiivisimmat käyttäjät tuntuvat pitävät tätä pelin henkenä. Kuten todellisuusohjelmienkin kohdalla usein ajatellaan, myöskään palstalla ei lopulta ole niin oleellista, mikä on totta ja mikä ei, kunhan viihdearvo ja tunnepotentiaali säilyy (vrt. Hautakangas 2005, 155-156). Tällaisessa ironisessa luennassa normit, maut, arvot ja moraali ovatkin jatkuvan neuvottelun ja pelin kohteena, eikä esimerkiksi ohjelman herättämiin moraalikysymyksiin tarvitse ottaa kantaa. 
Big Brother -keskustelupalsta ei kuitenkaan ole pelkästään ironinen arvotyhjiö, vaan esiin pyrkii myös äänenpainoja, jotka peräänkuuluttavat moraalista vastuuta ja tiettyjen sosiaalisten normien noudattamista myös verkkokeskusteluissa:

Kirjoittaja: pokerplayer

Aika: 18.11.2005 0:39

Aihe: Tää oikeiden ihmisten arvostelu on aika kauheeta

Tää ei ehkä oo ihan kivaa, että me täällä arvostellaan oikeita eläviä ihmisiä kovin rankasti. Toi talo on varmaan aika kummallinen paikka elää ja olla monta viikkoa. Ja sitten kun ihmiset tulee sieltä ulos yksi kerrallaan ja vastassa on kauhea haukkumistulva, niin voi siinä olla mielenterveys koetuksella.

Ehkä meidän pitäisi muistaa, että noi on oikeita ihmisiä, eikä mitään roolihahmoja.

Ironista ja affektiivista vastaanottoa kyseenalaistetaan juuri siksi, että viihteen kohteena on "oikeita ihmisiä": voiko todellisuusviihde voi olla "vain viihdettä"? ${ }^{8}$ Vaikka Big Brotherin katsojat puolustelevat esimerkiksi jonkun kilpailijan haukkumista rumaksi, tyhmäksi ja pahaksi ihmiseksi tai vaikkapa huonoksi äidiksi sillä, ettei moitteita ole esitetty kovin vakavissaan, loukkaa nimittely silti kritiikin kohdetta ja hänen läheisiään. Kohdetekstin arvomaailmaan aktivoitu yleisö tuottaa kuitenkin nykyisen mediakulttuurin toimintalogiikan hyvin tunnistavia, jopa kyynisiä vastauksia:

Kirjoittaja: MK781

Aika: 18.11.2005 0:42

Aihe: Tää oikeiden ihmisten arvostelu on aika kauheeta

jos taloon lähteee niin pitäs tietää mitä tulevan pitää. Siksi ite en lähtis.

Kirjoittaja: Pertti.Keinonen

Aika: 18.11.2005 1:19

Aihe: Tää oikeiden ihmisten arvostelu on aika kauheeta

No ei ole ehkä kivaa, mutta siihenhän koko tämä formaatti perustuu.

Tirkistellään ihmisiä milloin meitä huvittaa, ja vaikka kaikki noista kilpailijoista varmasti ovat oikeassa elämässä ihan mukavia ja sosiaalisia ihmisiä, niin 24h-tarkkailuilla heistä saadaan revittyä kaikki ärsyttävät piirteet esiin.

Sanoisin, että kaikki noista talossa elelijöistä on ehkä ihan tarkoituksella valittu sellaisia piirteitä silmälläpitäen, että joku 'keskivertokatsoja' kokee, että tuollainen tyyppi voisi olla ihan hyvä kaveri, mutta ei mikään sydänystävä tai aviopuoliso sentään. Ja kun heitä seurataan $24 / 7$, niin aina löytyy joku ärsyttävä piirre, josta voidaan jauhaa inhotusta.

Ja tähän koko formaatti perustuu. [...] Ja tuo äänestysprosessikin: On ihan tarkoitushakuista negatiivista mielentilaa aiheuttavaa se, että siinä käsketään kilpailijoita äänestämään tyyppejä pois, 
ja pyydetään meitä katsojia äänestämään samaten tyyppejä pois talosta. Tämä ihan tarkoituksella poikii keskusteluja, joissa ruoditaan pelaajien negatiivisia puolia. [...]

Se nyt vaan, ikävä kyllä, on paljon helpompaa saada katsojat koukkuun esittämällä henkilöitä siten, että heistä saa negatiivisia kuvia, kuin että katsojat täytyisi jotenkin houkutella pitämään kilpailijoista..

Kertoneeko tämä jotain ihmisluonnosta, ikävä kyllä..

\section{PELAAJIA, EI PELINAPPULOITA?}

Tuotanto- ja televisioyhtiöiden ohjelmiensa yhteydessä tarjoama vuorovaikutteisuus ja palautekanavat, kuten juuri verkkoyhteisöt, ovat paitsi uusi mediatekstien muoto ja yleisölle tarjottava lisäpalvelu, myös osa ohjelman markkinointia. Interaktiivisuuden avulla "koukuttamalla" ja "faniuttamalla" pyritään saamaan ohjelmille vankka vakiintunut seuraajajoukko, joka puolestaan houkuttelee mainostajia (vrt. Nikunen 2005, 102-103; Laukkanen 2003; myös Herkman 2005, 241-243). Tämä ei toki ole sinänsä aivan uusi ilmiö, sillä suomalaista TV-faniutta (myös verkkokäyttäytymistä) tutkinut Kaarina Nikunen toteaa, että televisiosarjojen tuottajat ja TV-yhtiöt ovat nähneet yleisöt faneina ja nimenomaan pyrkineet faniuttamaan katsojia jo ennen internetin yleistymistä, jopa 1980-luvun lopulta. Tuottajat ovat pyrkineet vuorovaikutukseen fanien kanssa ja näin ikään kuin testanneet tuotteitaan muun muassa osallistumalla fanikeskusteluihin, ja fanit ovat puolestaan voineet painostaa ohjelmien sisällön kehittämisessä tai jopa osallistua sarjojen käsikirjoittamiseen. Internet on kuitenkin helpottanut ja vahvistanut tätä kehitystä. (Nikunen 2005, 107-109.) ${ }^{9}$

Aktivoidulle yleisölle on luonteenomaista tekstin ja yleisön välisen vuorovaikutussuhteen tunnistaminen, itsensä identifioiminen katsojaksi ja kuluttajaksi eli osaksi vuorovaikutteista valtarakennetta, jossa yleisö on yhtäaikaisesti sekä mediatekstin hyväksyvä tai hylkäävä loppukäyttäjä, mainostajille kohderyhmänä myytävä tuote että osallistumisen kautta myös osa tekstin tuotantoa. Tällainen mediakulutuksen tapa eli yleisöys (katsojuus olisi liian passiivinen termi kuvaamaan tällaista multimodaalista yleisön toimintaa) on korostuneen kriittistä ja (itse)refleksiivistä, sillä median sisältöjä ja niitä ohjaavia motiiveja kyseenalaistetaan jatkuvasti mediakulutuksen yhteydessä. Tiivistäen, aktivoitu yleisö tietää paikkansa ja arvonsa kaupallisessa mediakulttuurissa - joskaan tämä ei tarkoita, että tähän tiedostamiseen liittyisi vastustusta tai pyrkimystä vallitsevan asiaintilan muuttamiseen.

Aktivoitu yleisö siis tunnistaa pelin hengen, ja samaa metaforaa käyttäen, tämä tunnistaminen tuottaa tunteen mukana pelaamisesta pelin kohteena olemisen sijaan. Big Brother -keskustelupalstalla tätä kuvastaa hyvin runsas tuotannon onnistumista arvioiva keskusteluः yleisö haluaa tulla viihdytetyksi, eikä viihdettä oletetakaan syntyvän pelkästä "tavallisuudesta" ja todellisuuden esittämisestä kameroiden välityksellä, vaan tuotannon on osattava ohjata tapahtumia ja vielä paketoida ne yleisölle vauhdikkaaseen ja viihdyttävään muotoon (vrt. Hill 2005, 179). Myös kilpailijoiden käytöksen ja talossa muodostuvien sosiaalisten tilanteiden (romanssit, konfliktit, ystä- 
vyyssuhteet, juonittelut) yleistä viihdyttävyyttä arvioidaan tuotannon eli erityisesti castingin onnistumisena tai epäonnistumisena. Jos jotakuta henkilöä pidetään mitäänsanomattomana tai koko Big Brother -yhteisöä liian värittömänä, kilpailijoiden syyttämistä tavallisempaa on sanoa, että "tuotanto ei osaa hommaansa":

Kirjoittaja: Strawbs

Aika: 2.09.2005 15:08

Aihe: Suomessa ei osata leikata/editoida tosi -tv:tä

Mua härnää se ammattitaidottomuus mikä suomalaisessa tosi tv:ssä on kun puhutaan yhden jakson yhteen leikkaamisesta.

Suomen Robinson oli suorastaan tylsä ja BB jatkaa samaa mallia.

Yksi kuva sanoo enemmän kuin tuhat sanaa jos sen osaa valita oikein. Tärkein osa näiden tosi tv ohjelmien kannalta on hyvä editointi.

$[\ldots]$

Miten voi olla Suomessa aina niin vaikea otta lainaksi ulkomailta ammattitaitoisia editojia jotta saataisiin sitä tosi-tv ideaa OIKEESTI ja ONNISTUNEESTI tännekin.

Tosi-tv ei ole todellista, se on katsojalle mielikuvien luomista oikealla editointi tyylillä.

Kirjoittaja: Motorcade

Aika: 18.10.2005 13:44

Aihe: BB-uutisissa "kevyttä" vihjailua Timosta ja Kathysta Kuvakulmien valinta, leikkaukset, kilpailijoiden "psyykkaus" pk-huoneessa, merkitsevät kysymykset Talk Show'ssa, viikkotehtävien parivalinnat jne. jne.

Rautaisia ammattilaisia on puikoissa ja rahaa niin paljon kiinni, ettei yksinkertaisesti ole varaa tehdä draamaköyhää sarjaa.

Tämähän on kaiken lisäksi hyvin kriittistä aikaa, kun eka tuotantokausi menossa.

Koska Big Brother on reaaliaikainen mediatapahtuma, yleisöllä on todella mahdollisuus vaikuttaa tarinan kulkuun. Kilpailijoille annettuja tehtäviä, rangaistuksia ja asukkaiden kohtelua arvostellaan, ja lisäksi esitetään suoria tehtävä-, rangaistus- ynnä muita toimintaehdotuksia tuotannolle. Vuorovaikutus ei ole vain näennäistä, sillä Big Brotherin tekijät seuraavat keskustelupalstan mielipiteitä ja ehdotuksia. Suomessa tästä puhuttiin keskustelupalstalla jo ensimmäisen tuotantokauden aikana, mutta tuotannon puolelta asia tuotiin selkeästi päivänvaloon vasta toisella tuotantokaudella, jolloin Big Brother -sivustolla kerrottiin asiasta suorasanaisesti, kiitettiin aktiivisia keskustelijoita ehdotuksista ja palautteesta ja jopa siteerattiin joitakin nettikirjoituksia nimimerkkeineen.

Tämä on osoitus siitä, kuinka Big Brotherin pyrkimys kutsua katsojat vuorovaikutukseen ja "osaksi tekstiä" toimii käytännössä. Juuri nämä osallistuvat Big Brotherin seuraajat kokevat seuraamiskokemuksen omakseen, ei pelkästään heitä varten tehdyksi; heillä on siis tunne vallasta suhteessa omaan me- 
diakokemukseensa. Big Brother -kokemus on siis tekstin ja yleisön, tuotannon ja yleisön (eli kaupallisesti ajateltuna kohderyhmän) sekä yleisön jäsenten keskinäisten samanaikaisten vuorovaikutussuhteiden monitasoinen verkosto. (Vrt. Tincknell \& Raghuram 2004.)

\section{HORJUUKO ISOVELJEN VALTA?}

Osallistava mediakulttuuri ja internet mahdollistavat myös markkinakriittisten äänten entistä laajemman kuulumisen. Pamela Wilson kirjoittaa Big Brotheriin Isossa-Britanniassa liittyneestä media- ja kulttuurihäirinnästä (media jamming, culture jamming). Wilson kuvaa katsojien yrityksiä rikkoa Big Brother -tuotannon kontrolli ja jopa tehdä tuotannon jatkuminen mahdottomaksi, esimerkiksi lähettämällä viestejä Big Brother -taloon ja yllyttämällä asukkaita keskeyttämään kilpailu. (Wilson 2004.) Myös Suomessa koettiin ensimmäisen Big Brother -tuotantokauden aikana Wilsonin kuvaamaan kulttuurihäirintään rinnastuva tapaus, joka sai myös suhteellisen paljon mediahuomiota. Ryhmä nuoria miehiä tunkeutui muurien yli kiipeämällä $B B$-taloon ja alkoi pitää juhlia talon pihamaalla. Kyseessä oli baari-illan päätteeksi mieleen juolahtanut kolttonen, reaaliaikaisen mediatapahtuman mahdollistama julkisuustemppu. Wilson toteaa Big Brotherin houkutelleen kulttuurihäiritsijöitä juuri "siksi, että se oli mahdollista" (Wilson 2004, 339). Merkillepantavaa on kuitenkin, että tuotannon kontrollia ohjelman ja sen imagon suhteen horjutettiin, joskin vain väliaikaisesti.

Keskustelupalstalla luvaton tunkeutuminen kiinnitti runsaasti huomiota. Aluksi epäiltiin, oliko koko tunkeutumista todella tapahtunut; sittemmin tapahtumien varmistuttua alettiin toisaalta moittia tunkeutujia ohjelman pilaamisesta, toisaalta kiitellä hauskasta pilasta. Paljon puhetta herätti tapahtuman mahdollinen julkisuusarvo, mikä tuo jälleen hyvin esiin aktivoidun yleisön suhtautumisen mediaan pelinä tai kamppailuna:

[vastauksena yhden murtautujan kirjoittamaan viestiin, jossa kertoo joukkion myyneen kuvia tapahtuneesta 7Päivää -lehdelle:] Kirjoittaja: lisa123

Aika: $12.09 .20059: 59$

Aihe: Big Brother taloon murtauduttiin!?

Toivottavasti saitte jo rahat seiskalta, koska voi olla aika menneen talven lumia koko uutinen ennen kuin seiska ilmestyy. Iltalehtihän on samaa konsernia Sub Tv:n kanssa, eli niillä on tapahtumasta varmasi vähintään yhtä hyvät kuvat kuin teillä talossa olevien kameroiden ansiosta. Ehkäpä ei olisi kannattanut niin hehkuttaa tapauksella täällä, koska näköjään Sub Tv oli ensin ajatellut pitää koko tapauksen salassa, mutta kun huomasi ettei pysty, niin julkaisi itse jutun ensimmäisenä Iltalehdessä ja sai itselleen jutun uutisarvon. Jos olisitte pelanneet fiksummin, niin olisitte olleet ihan hiljaa siihen asti kun juttu on julkaistu seiskassa. 
Kriittisimmilleen tuotantoa kohtaan keskustelu yltyi, kun keskustelijat totesivat ylläpidon poistaneen palstalta useita aiheeseen liittyneitä viestiketjuja, joskin tuotannon puolestapuhujiakin löytyi:

Kirjoittaja: deltius

Aika: 11.09.2005 23:20

Aihe: Big Brother taloon murtauduttiin!?

Pitääkö paikkansa? Paljon ollut päivällä keskustelua tuosta. Nä-

köjään viestiketjujakin poistettu tältä forumilta, subtv haluaa kai selvästi peitellä asiaa.

Kertokaa ketkä tiedätte asiasta enemmän.

Kirjoittaja: deltius

Aika: 12.09.2005 9:19

Aihe: Big Brother taloon murtauduttiin!?

tämä on vain veikkaus, mutta syynä näiden viestiketjujen poistamiseen saattaa olla se, etteivät he halua kannustaa ihmisiä tekemään samanlaisia tempauksia jatkossa. [...]

Kirjoittaja: pleijeri

Aika: 12.09.2005 14:33

Aihe: Big Brother taloon murtauduttiin!?

Onnee vaan porukalle mikä taloon pääsi. Hyvin vetää SubTv nää turvallisuusseikat,luulis ton talon ollu vähän paremmin vartioitu. [...] Onko muuten kilpailijoille ilmoitettu tapahtumasta, vai aiotaanko he jättää tietämättömiksi tapahtumista?

Tunkeutuminen ja sen seuraukset tarjoavat hyvän esimerkin tuotannon ja yleisön valtakamppailusta. On kuin onkin olemassa rajat sille, missä määrin tuotanto antaa yleisölle äänivaltaa ja tilaa itseensä kohdistuvalle kritiikille. Heti tapahtuneen jälkeen keskusteluja poistettiin, mutta myöhemmin keskustelun annettiin jatkua - mahdollisesti tällä välin tehtiin päätös, kuinka tuotanto tiedottaisi tapahtuneesta. Tuotanto onnistui lopulta käsittelemään koko episodin varsin jouhevasti ja tekemään siitä osan "BB 2005" -tarinaa, eikä esimerkiksi tuotannon kyvystä taata kilpailijoiden turvallisuus noussut sen suurempaa kohua.

Myös Tincknell ja Raghuram ovat varuillaan sen suhteen, missä määrin Big Brother -yleisön aktiivisuuden voi tulkita vastarintaiseksi tai vapaaksi tuotannon hallinnasta. He toteavat, että vaikka Big Brotherin yleisön osallistumista koko mediaspektaakkelin tuottamiseen voidaan pitää sekä tähän asti laajimpana populaarissa televisioviihteessä että myös oleellisena tekijänä formaatin menestykselle, on kiistanalaista, missä määrin tämä osallistuminen tuotti valtaa määritellä tekstin tarjoamia merkityksiä. (Tincknell \& Raghuram 2004, 264.)

Hegemoninen taistelu merkityksistä, totuuksista ja markkinavallasta yleisön ja tuotannon välillä ei siis katoa vuorovaikutuksen lisääntymisen myötä, mutta tulee kenties entistä näkyvämmäksi. Hyvä esimerkki yleisön tiedostavasta asenteesta on myös Big Brotherin tuotesijoittelusta käyty keskustelu: 
Kirjoittaja: Viivu

Aika: 1.11.2005 21:05

Aihe: $B B: n$ vaikutus kulutuskäyttäytymiseenne?

Onko kuinka monella täällä sama ongelma, että BB vaikuttaa siihen mitä ostatte? Tänään oli pakko ostaa Maraboun minttukrokanttilevy, vaikka normaalisti en edes suklaata osta, enkä yleensä mitään muutakaan karkkia. [...]

Kirjoittaja: IsoVelli3

Aika: 1.11.2005 21:15

Aihe: BB:n vaikutus kulutuskäyttäytymiseenne?

Tästä Subin product placementistahan on varmaan tutkintapyyntö olemassa. Noin suoraan ei ohjelmissa saa mainostaa tuotteita. Harmaalla alueella Sub liikkuu

Kirjoittaja: tkeidas

Aika: 1.11.2005 21:34

Aihe: $\mathrm{BB}: n$ vaikutus kulutuskäyttäytymiseenne?

Tämähän oli puheenaihe heti alkupäivinä. Nyt BB:tä on jatkunut jo pari kuukautta ilman mitään muutosta. Minusta tuossa ei ole kyse piilomainonnasta vaan aivan rehdistä sponsoroinnista. Eihän tukijoita ole yritetty ottaa vaihvihkaa mukaan, vaan esimerkiksi R-Kioski on oleellinen osa lavasteita.

Viestintävirasto todella antoi Subtv:lle huomautuksen piilomainonnasta Big Brotherissa. Merkillepantavaa on kuitenkin se, että katsojat tuntuivat ennemminkin riemuitsevan omasta medialukutaidostaan eli siitä, että kykenivät tunnistamaan tuotesijoittelun (ja myös muita tuotannon taustalla vaikuttavia kaupallisia kytköksiä, esim. musiikkivalintojen ja levy-yhtiöiden omistuspohjan suhteen).

\section{LOPUKSI: AKTIVOIDUN YLEISÖN POLIITTISUUS?}

Olen edellä esittänyt Big Brotherin yleisön internetin keskustelupalstan analyysiin pohjautuen, että nykyisessä populaarissa mediakulttuurissa on muotoutunut (ja muotoutumassa) yleisöksi asettumisen tapa, jolle on ominaista 1.) vahva tietoisuus omasta roolista "yleisönä" ja kuluttajana mediamarkkinoilla eli osana kulttuuriteollisuuden rakenteita; 2 .) virittyminen samaan diskurssiin tekstin kanssa ja (usein ironian sävyttämä) vahva affektiivinen panostus tähän mediasuhteeseen; sekä 3.) aktiivinen vuorovaikutus tekstin ja tuotannon kanssa. Tässä yleisön, tekstin ja tuotannon vuorovaikutussuhteessa yleisö tulkitsee mediatekstejä ja tuottaa niistä merkityksiä. ${ }^{10}$

Näen tällaisessa aktivoiduksi yleisöydeksi nimittämässäni merkityksenantoprosessissa positiivista potentiaalia, sillä se vaikuttaa lisäävän keskustelua ja yleisön tietämystä mediatodellisuuden taustarakenteista - sekä tekstien ja niiden merkitysten muodostumiseen vaikuttavista tekijöistä että taloudellisista kytköksistä. Lisäksi vuorovaikutteiset formaatit, joista kenties interaktiivisin on juuri Big Brother reaaliaikaisuutensa ja yleisökeskusteluja tarkkaan seuraavan tuotantonsa vuoksi, mahdollistavat edes jossakin määrin yleisön 
osallistumisen itse tekstin (ja näin myös merkitysten) tuotantoon (ks. van Zoonen 2005, 55). Vaikka mediatekstien tuottajilla tulee epäilemättä tulevaisuudessakin olemaan viime kädessä valta tarjoiltavien merkitysparadigmojen suhteen, erilaisten vaikutusrakenteiden tunnistaminen mahdollistaa niiden kyseenalaistamisen ja haastamisen samanaikaisesti niiden kuluttamisen kanssa.

Todellisuustelevision yleisöjä tutkinut Annette Hill puhuu niinikään optimistisesti yleisön kriittisestä katsojuudesta (critical viewing) ja sen positiivisista vaikutuksista medialukutaitoon. Hilliä voi tulkita siten, että erityisesti nuorten tapa katsoa todellisuustelevisiota kriittisesti ja kyseenalaistaen on yksi osoitus siitä, miten ihmisten medialukutaito kehittyy sille esitettyjen vaatimusten lisääntyessä. (Hill 2005, 187-189.) Liesbet van Zoonen puolestaan rinnastaa Big Brotherin ja Idolsin kaltaiset aktiiviset populaarit faniyhteisöt poliittiseen toimintaan, ja näkee mahdollisuuden jopa kehittää uudenlaista poliittista kulttuuria ja kansalaisuutta etsimällä näihin "vakaviin" yhteiskunnallisen toiminnan muotoihin malleja niistä populaarien tekstien puhuttelutavoista, jotka synnyttävät esimerkiksi faniaktiivisuutta (van Zoonen 2005, 58-67). Ajatukseni aktivoidusta yleisöstä liittyy tähän keskusteluun yhtenä pyrkimyksenä hahmottaa näitä puhuttelutapoja ja analysoida populaarikulttuurin piirissä syntyvää yhteisöllisyyttä, ottaen huomioon myös populaarien/ viihteellisten tekstien yhteiskunnallis-poliittiset ulottuvuudet ja merkitykset (vrt. Gray 1999, 23-24).

En toki väitä, että kaikki yleisöt olisivat samasta puusta veistettyjä tai että "aktivoituminen" olisi ainoa tapa nauttia populaarikulttuurista tai todellisuustelevisiosta - tai edes että kaikkien Big Brotherin verkkokeskusteluihin osallistuvien osallistumistapa olisi samanlainen. Kuten Birgitta Höijer osuvasti muistuttaa, kaikki mediakulutus ei ole aktiivista, eikä aktiivisuus aina välttämättä tarkoita "sitä mikä on parasta yleisölle" (Höijer 1999, 191). Pidän tätä yleisöksi aktivoitumista kuitenkin niin leimallisena koko reality-ilmiölle ja sitä koskevalle keskustelulle, että sen ymmärtäminen voisi auttaa vastaamaan myös kysymykseen mikä tosi-TV:ssä kiinnostaa. Näin on mahdollista ohittaa ajatus todellisuustelevisioilmiöstä tiettyihin formaatteihin rajoittuneena muotioikkuna, jonka odotetaan menevän ohi, ja keskittyä siihen yleisön ja median välisen suhteen kehitykseen, joka on mahdollistanut tällaisten sisältöjen suosion, ja jonka voi olettaa johtavan osallistavien, monimediaalisten mediatuotteiden tuotantoon ja kulutukseen myös tulevaisuudessa. On varmasti olemassa rajansa siinä, kuinka monta tuotantokautta Big Brotheria, Survivoria tai mitä tahansa muuta reality-formaattia voidaan menestyneesti tuottaa, mutta yleisön roolia osana mediatekstin muodostumista hyödyntäviä tullaan varmasti näkemään yhä lisääntyvässä määrin. Pelimaailman ja verkottuneen mobiiliteknologian kehitys ja konvergenssi television kanssa pitävät osaltaan tästä huolen. 


\section{Viitteet}

1 Olen aiemmin käyttänyt termiä" yliaktiivinen yleisö" erityisesti tällaisen yleisön voimakkaiden affektiivisten panostusten takia, mutta"yliaktiivisuus" herättää mielikuvia lähinnä aktiivisuuden liiallisuudesta ja hallitsemattomuudesta," huonosta aktiivisuudesta", ja johdattaa näin ollen hieman harhaan niistä näkökulmista, joita itse asiassa haluan tuoda esille. Olen korvannut termin mielestäni osuvammin painottuvalla aktivoidun yleisön käsitteellä.

2 Big Brotherista monimediaalisena seuraamiskokemuksena ks. Rasimus 2006

3 Big Brother -aiheisia keskusteluja käytiin toki myös monilla muilla internet-foorumeilla, kuten iltapäivälehtien TV-ohjelmia käsittelevillä keskustelupalstoilla, Suomi24.fi-palvelussa sekä erityisillä Big Brotherin fanisivustoilla (esim. http://www.bbplaza.net/, http://www.suomenbb. $\mathrm{com} /$ ). Virallisen keskustelupalstan valinta tutkimuksen kohteeksi oli kuitenkin selvä paitsi sen suosion ja vilkkauden vuoksi, myös erityisesti siksi, että tämä palsta oli kytköksissä ohjelman tuotantoon ja kuului osana Big Brotherin tuotannon määrittelemään tekstiin.

4 Ohjelmien viehätys ei myöskään piile sinänsä totuuden ja toden paljastamisessa, vaan tavallisten ihmisten kokeman todellisuuden esittämisessä (vrt. alkuperäinen termi" reality" tai"real life" - ei"true"). Reality-ohjelmat ovat myös luonteeltaan hyvin erityyppisiä alkuperämaasta riippuen (esim. UK vs. USA). Reality television -tyyppisistä ohjelmista ilmiönä puhuttaessa käytän mieluummin nimityksiä todellisuustelevisio tai -viihde, mutta toisinaan esimerkiksi yleisökeskusteluun viitattaessa käytän selvyyden vuoksi myös yleiseen käyttöön vakiintunutta termiä "tosi-TV". Tarkemmin omasta käsitteenmäärittelystäni ks. Hautakangas 2005; reality-viihteen kehityksestä ja eri muodoista ks. Hill 2005, 14-40.

5 Suomi ei tee tässä poikkeusta, vaikka täällä kyseinen formaatti otettiinkin tuotantoon vasta siinä määrin myöhään (syksyllä 2005, kun formaatin suosio alkoi maailmalla jo 1999), että suuri osa ohjelmaan muualla maailmassa liitetystä "moraalipaniikista" oli ehditty käydä läpi muiden reality-formaattien, kuten Miljonääri-Jussin (MTV3 2004), kohdalla. Samat moraalikritiikin aiheet, kuten nuorten aikuisten alkoholinkäyttö, seksuaalikäyttäytyminen ja julkisuushakuisuus ovat kuitenkin tapetilla yhä myös Big Brotheria koskevassa julkisessa keskustelussa.

6 Hillin käyttämä yleisnimitys"tosi-TV:lle".

7 Diskurssin määritelmästä ks. esim. Lehtonen 1994, 34; Pälli 2003, 22-23.

8 Yleisön kriittisyydestä todellisuusviihdettä kohtaan vrt. Hill 2005, 186-188.

9 Nikunen toteaa myös, että Suomessa erityisesti Subtv on hyödyntänyt faniyleisöjä ja faniuttamista rakentamalla ohjelmistonsa erilaisten fanikulttuurien suosimien sarjojen ympärille (Nikunen 2005, 104). Oman tutkimukseni pohjalta voin yhtyä Nikusen näkemykseen; myös Big Brotherin tuotannossa ja markkinoinnissa Subtv on hyödyntänyt aktiivisesti katsojien faniuttamista ja vuorovaikutusta näiden ja tuotannon välillä, kuten tuonnempana käy ilmi. Tässä valossa ei ole yllättävää, että tämä maailmalla huippusuosittu formaatti päätyi Suomessa juuri (etenkin vielä syksyllä 2005 suhteellisen marginaaliselle) Subtv:lle.

10 Tällaista katsojuutta voi halutessaan nimittää postmoderniksi (vrt. esim. Ang 1996).

11 Todellisuustelevisioviihteen viehätys ja kulttuurinen paikantaminen on kohteena laajemmassa tutkimuksessani, johon tämä artikkeli liittyy yhtenä osana ja työkaluna. 


\section{Kirjallisuus}

Alasuutari, Pertti (1999) Introduction: Three Phases of Reception Studies. Teoksessa Alasuutari, Pertti (ed.): Rethinking the Media Audience: The New Agenda. London, Thousand Oaks and New Delhi: Sage, 1-21.

Ang, Ien (1985) Watching Dallas: Soap Opera and the Melodramatic Imagination. London \& New York: Routledge.

Ang, Ien (1996) Living Room Wars. Rethinking Media Audiences for a Postmodern World. London \& New York: Routledge.

Bailey, Steve (2002) Virtuality and the Television Audience: The Case of Futurama. The Communication Review, 5:239-257.

Biltereyst, Daniel (2004) Reality TV, Troublesome Pictures and Panics: Reappraising the Public Controversy Around Reality TV in Europe. Teoksessa Su Holmes \& Deborah Jermyn (eds.): Understanding Reality Television. London \& New York: Routledge, 91-110.

Fiske, John (1989) Understanding Popular Culture. London and New York: Routledge. Glynn, Kevin (2000) Tabloid Culture: Trash Taste, Popular Power, and the Transformation of American Television. Durham: Duke University Press.

Gray, Ann (1999) Audience and Reception Research in Retrospect: The Trouble with Audiences. Teoksessa Alasuutari, Pertti (ed.): Rethinking the Media Audience: The New Agenda. London, Thousand Oaks \& New Delhi: Sage, 22-37.

Grossberg, Lawrence (1995) Mielihyvän kytkennät: Risteilyjä populaarikulttuurissa. Suomentaneet ja toimittaneet Juha Koivisto, Mikko Lehtonen, Ensio Puoskari ja Timo Uusitupa. Tampere: Vastapaino.

Griffen-Foley, Bridget (2004) From Tit-Bits to Big Brother: a Century of Audience participation in the media. Media, Culture and Society Vol. 26(4), 533-548.

Hall, Stuart (1973) Encoding and Decoding in the Television Discourse. Birmingham: University of Birmingham.

Hautakangas, Mikko (2004) Juuri oikeenlaista kemiaa - romantiikka ja parisuhdeihanteet vertaismelodraamoissa Unelmien poikamies ja Escort. Pro gradu -tutkielma, Tampereen yliopisto.

Hautakangas, Mikko (2005) "Tavikset, tunteet ja moraali TV-viihteenä". Tiedotustutkimus 1/2005, 150-161.

Herkman, Juha (2005) Kaupallisen television ja iltapäivälehtien avoliitto: Median markkinoituminen ja televisioituminen. Tampere: Vastapaino 2005.

Hill, Annette \& Gareth Palmer (2002) Big Brother. Television \& New Media Vol. 3 No. 3 , Sage Publications, 251-254.

Hill, Annette (2005) Reality TV. Audiences and Popular Factual Television. London \& New York: Routledge.

Holmes, Su (2004) 'But This Time You Choose!' Approaching the 'Interactive' Audience in Reality TV. International Journal of Cultural Studies, Vol. 7(2): 213-231, Sage Publications.

Horkheimer, Max \& Theodor W. Adorno (2004 [1933]) Kulttuuriteollisuus. Valistus joukkohuijauksena. Suomentanut Veikko Pietilä. Tiedotustutkimus 4-5/2004.

Höijer, Birgitta (1999) To Be an Audience. Teoksessa Alasuutari, Pertti (ed.): Rethinking the Media Audience: The New Agenda. London, Thousand Oaks and New Delhi: Sage, 179-194.

Kellner, Douglas (1998) Mediakulttuuri. Suomentaneet Riitta Oittinen ja työryhmä. Tampere: Vastapaino.

Keskitalo, Tapio \& Antti Palomaa \& Sari Sainio (2005) Myyttinen Matti myy. Tiedotustutkimus 1/2005, 168-175.

Kilborn, Richard (2003) Staging the Real. Factual TV Programming in the Age of Big Brother. Manchester: Manchester University Press.

Laukkanen, Tero (2003) Fanituottajuuden kulta-aika. Digitaalinen mediateknologia ja osallistuva kulttuuri. Lähikuva 4/2003, 36-47.

Leed, Marika (2005) Se ei todellakaan ole mikään saippuasarja. Kotikatu-tv-sarjan verkkokeskustelut fanien tulkintayhteisönä ja neuvottelujen areenana. Pro gradu -tutkielma, Helsingin yliopisto.

Lehtonen, Mikko (1994) Kyklooppi ja kojootti. Subjekti 1600-1900 -lukujen kulttuuri- ja kirjallisuusteorioissa. Tampere: Vastapaino.

Magder, Ted (2004) End of TV 101. Reality Programs, Formats and the New Business of Television. Teoksessa Susan Murray \& Laurie Ouellette (eds.): Reality TV: Remaking 
Television Culture. New York \& London: New York University Press, 137-156.

Moran, Albert (1998) Copycat Television. Globalisation, Program Formats and Cultural Identity. Luton: University of Luton Press.

Murray, Susan \& Laurie Ouellette (2004) Reality TV: Remaking Television Culture, New York \& London: New York University Press.

Mäyrä, Frans (1999) Internetin kulttuurinen luonne: kaaosherroja ja verkonkutojia. Teoksessa Aki Järvinen \& Frans Mäyrä (toim.): Johdatus digitaaliseen kulttuuriin. Tampere: Vastapaino, 95-111.

Nikunen, Kaarina (2005) Faniuden aika. Kolme tapausta TV-ohjelmien faniudesta vuosituhannen taitteen Suomessa. Tampere: Vastapaino.

Pälli, Pekka (2003) Ihmisryhmä diskurssissa ja diskurssina. Tampere: Tampere University Press. Raphael, Chad (2004) The Political Economic Origins of Reali-TV. Teoksessa Susan Murray \& Laurie Ouellette (eds.): Reality TV: Remaking Television Culture, New York \& London: New York University Press, 119-136.

Rasimus, Mari (2006) Joka tuutista pitkin päivää. Monimediaalisuus Suomen Big Brotherin yleisön seuraamiskokemuksessa. Pro gradu -tutkielma, Helsingin yliopisto.

Tincknell, Estella \& Parvati Raghuram (2004) Big Brother: Reconfiguring the Active' Audience of Cultural Studies?. Teoksessa Su Holmes \& Deborah Jermyn (eds.): Understanding Reality Television. London \& New York: Routledge, 252-299.

Töyry, Maija (2005) Eliitit tarvitsevat Seiskaa. Tiedotustutkimus 1/2005, 161-167.

Wasko, Janet (2001) Understanding Disney: The Manufacture of Fantasy. Cambridge: Polity Press.

Wilson, Pamela (2004) Jamming Big Brother: Webcasting, Audience Intervention, and Narrative Activism. Teoksessa Susan Murray \& Laurie Ouellette (eds.): Reality TV: Remaking Television Culture. New York \& London: New York University Press, 323-343.

van Zoonen, Liesbet (2005) Entertaining the Citizen: When Politics and Popular Culture Converge. Lanham: Rowman \& Littlefield. 